\title{
Selecting Shopping Center Site Using MADM Techniques
}

\author{
Aliyeh Kazemi, Mitra Amiri
}

\begin{abstract}
Shopping malls are one of the glories of metropolises with their attractive shops and a wide variety people who are walking in order to purchase goods. Location selection decision making of these shopping malls is considered as a strategic decision, due to its noticeable impact on shopping malls profitability. Selection of an appropriate site requires consideration of multiple alternatives and assessment of attributes. Old solutions lack the ability to deal with linguistics variables (qualitative), on account of theirs ambiguity and imprecision. The aim of this paper is to integrate numbers of conflicting qualitative and quantitative variables for evaluating alternatives. Tehran is considered as a real example. Methodologically, Shannon Entropy is applied for assigning weights of each attribute. TOPSIS and VIKOR are utilized for ranking alternatives by computed weights. This model rectifies the deficits of old solutions with providing the grounds of decision making under uncertainty.
\end{abstract}

Keywords - Shopping center, MADM, Shannon Entropy, TOPSIS, VIKOR

\section{INTRODUCTION}

Where is the most suitable and profitable location for a shopping mall? Due to modernization, the shopping habits have changed from small independent stores or discount stores to large regional shopping malls. In this modern era, people have more positive views towards large shopping malls, due to the fact that people find buying in shopping malls as a unique process that leads to rise of attractiveness of shopping malls [1]. Finn and Louviere, demonstrated that people have negative perceptions toward the quality of goods and services in discount stores [2]. Based on their views, large shopping malls provide goods and services of high quality, wide selection, and latest styles.

On the grounds of this importance, what makes shopping malls more interesting places? Or what are the sources of customers' satisfaction about shopping malls? Anselmsson, found that eight underlying factors play the key roles in making customers pleased [3]. These are selection, atmosphere, convenience, sales people, refreshments, location, promotional activities and merchandising policies. It is clear that location is considered as one of the sources of customers' satisfaction.

Two noteworthy questions are under consideration, why the location selection is important and for whom is it important? The replies are as follows respectively. It has noticeable effects

Manuscript received Aug. 26, 2016.

Aliyeh Kazemi is with Department of Industrial Management, Faculty of Management, University of Tehran, Tehran, Iran.

Mitra Amiri is with Department of Business Management, Faculty of Management, University of Tehran, Tehran, Iran. on the future profitability and attractiveness of shopping malls; likewise the findings of Leo and Philip, which showed the tie of customer satisfaction with areas and districts of commercial shopping in general [3]. Therefore, a well suited location can attract a large number of customers due to the fact that it will be accessible for the majority of residents [4]. Another point is that the location decisions have the critical importance for all firms and more specifically for businesses that rely on customers [5]. It means that those businesses which have not got any physical contact with customers, demand for the products or services which are relatively independent of locations and vice versa [6].

The crucial importance of selecting the most suitable location is often undervalued, whereas this manner affects marketing and financial strategy of retailers who will be active in the shopping malls $[1,5]$. To retailing businessmen, how to attract customers and catch the opportunities of marketplace development are the two most noticeable issues in practice. Contrary to all of these reasons, investors usually pay a very little attention to this matter, owing to the fact that it is one of the most difficult and complicated issues to plan. In the same respect, since there are a number of potential locations which have their strengths and weaknesses, determination and evaluation of positive and negative characteristics of one location relative to others is a challenging, time-consuming task $[2,5,7]$.

In brief, a comprehensive site study should be made based on the characteristics of that special industry and its future, in advance of the decision making process so as to opt for the suitable site location [8]. The suitable location is a general term defined by many various factors; for instance, accessibility, total cost of initial investment, environmental consideration, potential continuous development, etc. Hence, during the stage of making a decision, a lot of attributes should be considered and the decision should be made on the basis of mentioned factors. As attributes and alternatives increase, it becomes very demanding and almost impossible for a human brain to analyze the relation between all attributes and alternatives to make the best decision [9].

Traditional decision support techniques lack the ability to simultaneously take these attributes and alternatives into account [10]. Moreover, these models lack the ability to give the correct weights to the attributes. Consequently, these attributes are sorted out and assessed subjectively [8,11]. Nowadays more sophisticated methods are introduced with the aim of providing more logical and convincing results. MADM ${ }^{1}$ techniques deal with the process of making decisions for finding the optimum alternative in the presence of multiple,

\footnotetext{
${ }^{1}$ Multiple Attribute Decision Making
} 
usually conflicting attributes [12]. Thus, the mall location selection problem could be progressed with the mentioned MADM methods.

To summarize, the process of site selection typically involves two main phases: screening (identifying a limited number of candidate sites from a broad geographical area given a range of selection factors) and evaluation (in-depth examination of alternatives to determine the most suitable site). It should be marked that multitude contradictory factors are involved in both phases [13].

The aim of this article is to find the most suitable location for shopping malls on account of attracting shoppers and affecting market shares and profits. As Kotler said "the key to achieving organizational goals consists in determining the needs and wants of target markets and delivering the desired satisfactions more effectively and efficiently than competitors" [14]. This research has a new perspective to solve this kind of problem. The MADM techniques are powerful tools for solving this sort of managerial decisions with multiple attributes.

The rest of the paper is organized as follows: the related studies are summarized in section II. Section III, presents the methodology including Shannon Entropy, TOPSIS ${ }^{2}$, and VIKOR $^{3}$. Next, section IV contains the result of numerical example and in section V finally the article is concluded.

\section{LITERATURE REVIEW}

Site selection has been identified as one of the key factors to achieve strategic objectives and to progress a right project. Therefore, those decisions, which are related to it, should be made with great cautious owing to the fact that location has been validated as an important determinant of shopping mall visit frequency.

Over the past decades the location selection models have increased significantly. These models are principally mathematical models that can be categorized into two groups: 1) static and deterministic, 2) dynamic and stochastic [2]. But, recent models for selection of an appropriate location have been changed. These models contain both quantitative and qualitative values with the concentration on end users' behaviors [15]. Among these models MADM models have been chosen for the present research. At first the discussion revolves around the location selection from other practitioners' point of view in different fields, since there are limited numbers of papers which discuss the location selection of shopping malls. And then proceed to attributes selection. The study on location selection started more than a century ago when Alfred Weber, tried to find the most suitable location of warehouse in order to have minimum distance with the customers [2]. Aikens, and Chen, utilized mathematical programming in order to process facility location model for a distribution center [16]. Siddiqui et al., was the first in applying geographical information system (GIS) and analytical hierarchy process (AHP) for site selection [7]. Similarly Cheng et al., proposed the GIS algorithms to select the shopping malls [2]. Korpela and Tuminen, employed

\footnotetext{
${ }^{2}$ Technique for order preference by similarity to ideal solution

${ }^{3}$ Multi- criteria optimization and compromise solution
}

AHP-based decision in which both qualitative and quantitative values are taken into consideration for adopting warehouse site selection [17]. Chen et al., utilized fuzzy multi objective approach in order to find the best site of fire station of an international airport [16]. This model helps to figure out the optimal number of sites of fire stations. Teng, utilized MCDM method for site selection of restaurants [16]. Chen, utilized MCDM method to deal with the distribution center location selection under fuzzy environment [18]. Chen et al., applied a fuzzy MCDM approach to solve the landfill selection problem in Canada [7]. Tzeng et al., processed MCDM models for a restaurant location in Tapei, China through AHP method [16]. Kuo et al., developed a decision support system for locating convenience store through fuzzy AHP and artificial neural network [4]. Cook and Green, proposed a model for the problem of location selection of new branches of store chain [15]. Kahraman et al., used fuzzy group decision making for facility location selection [18]. Cheng et al., demonstrated the effectiveness of the ANP to select the best site for a shopping center [2]. Onut and Sonner, applied AHP and TOPSIS and fuzzy condition for transshipment site selection [7]. Chou et al., used fuzzy MCDM for international tourist hotels location selection [16]. Guneri et al., used fuzzy ANP approach for shipyard location in Turkey [9]. Vahidnia et al., proposed fuzzy AHP for hospital site selection in Iran [13]. Mohajeri and Amin, proposed the AHP algorithm and Data Envelopment Analysis with the aim of selecting railway station in Iran [19]. Awasti et al., applied the fuzzy TOPSIS principles in order to select the urban distribution center location [20]. Kaya, processed a fuzzy AHP for wastewater treatment location selection [9]. Kuo, developed ANP and TOPSIS for international distribution center location problem [21]. Kengol et al., proposed a decision support system for selection of solar power plant location by combining fuzzy AHP and TOPSIS by GIS in order to reach optimum site [17]. Yaghoubzadeh, used GIS and AHP and TOPSIS for site selecting of cinema in Tehran, Iran [10]. Rezaeiniya et al., applied fuzzy ANP approach for greenhouse location selection in Iran [9].

\section{Methodology}

Planning for construction of a shopping mall in the crowded cities with different levels of income is a demanding and complicated task that, there is no stable method for this kind of decision making problems. In order to achieve this goal, several sites should be identified. Vanak Square (a populated region in the north-western of Tehran), Emam Hosein Square (a populated region in the south-eastern of Tehran), Marzdaran Boulevard (a thinly populated region in the west of Tehran), and Jomhori Square (a populated region in the south-western of Tehran) are determined as location alternatives in this research. In brief, they are named as A1, A2, A3, and A4 in the same order. Selecting the most well suited location is depending on measurable attributes [2]. The alternative that performs best with respect to all attributes is chosen for investment [20].

Based on the reviewed papers, numbers of attributes have been chosen. Next, experts discussed to establish the 
framework of attributes and sub-attributes for more precise analyses of selecting site location. It can be concluded that shopping malls site selection is viewed as a multiple attributes decision making problem. The attributes and sub-attributes are shown in Fig 1.

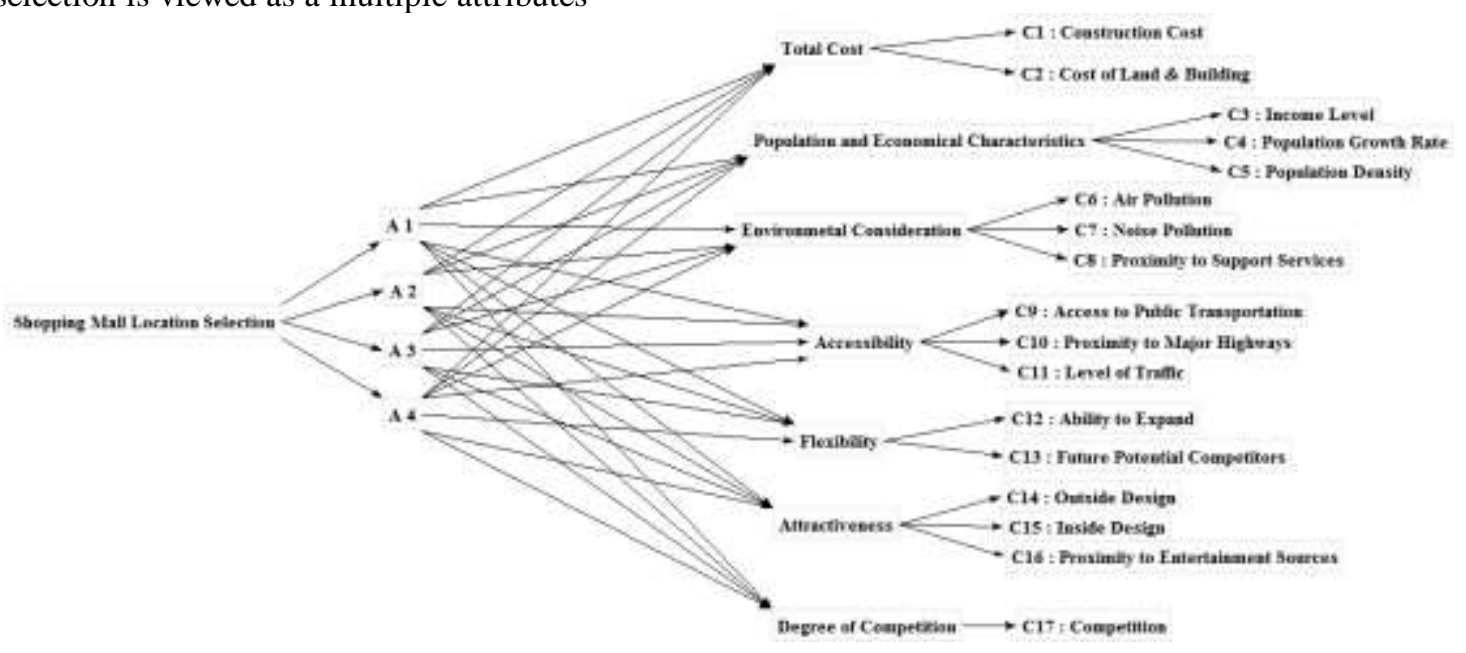

Fig. 1: Conceptual model of shopping mall site selection

For data collection a detailed questionnaire related to data, regarding to the sub-attributes for the location selection model was prepared. The experts have a crucial role in evaluation and calculating weights. Each expert ranked the alternatives based on the degree of each particular sub-attribute from very low to very high, which are linguistic assessment for evaluating the alternatives. Next, each expert ranked all the sub-attributes from the first to the last based on their importance with the use of their own implicit knowledge, information, and experiences. After determining the weight of each sub-attribute by Shannon Entropy, an MADM method (TOPSIS and VIKOR) could be applied to rank alternatives and to propose a solution to decision makers. These steps are shown in Fig 2 briefly.

\section{A. Shannon Entropy}

As mentioned before, two different weights are used in the proposed research: objective weights and subjective weights which are obtained directly from decision makers' opinions. Shannon, developed the entropy theory for expression of information or uncertainty. He defined a quantitative measure of uncertainty based on information content distribution in terms of entropy, called Shannon Entropy. Thus, entropy is a measure of the amount of uncertainty and of the amount of the lack of information about a system. If comprehensive information is available entropy $=0$. Otherwise, it is greater than zero [22,23]. In order to apply Shannon Entropy for computing weights, arithmetic mean are taken from experts' opinion about alternatives' importance and sub-attributes' importance.

The steps of Shannon Entropy are as followed:

Step 1: Normalize the evaluation index:

$p_{i j}=r_{i j} / \sum r_{i j}$

Step 2: Calculate entropy measure of every index:

$e_{j}=-k \sum p_{i j} \operatorname{Ln}\left(p_{i j}\right)$

$k=(\operatorname{Ln}(m))^{-1}$

Where $\mathrm{k}$ is a constant which guarantees $0<e_{j}<1$, and $\mathrm{m}$ is the number of alternatives.

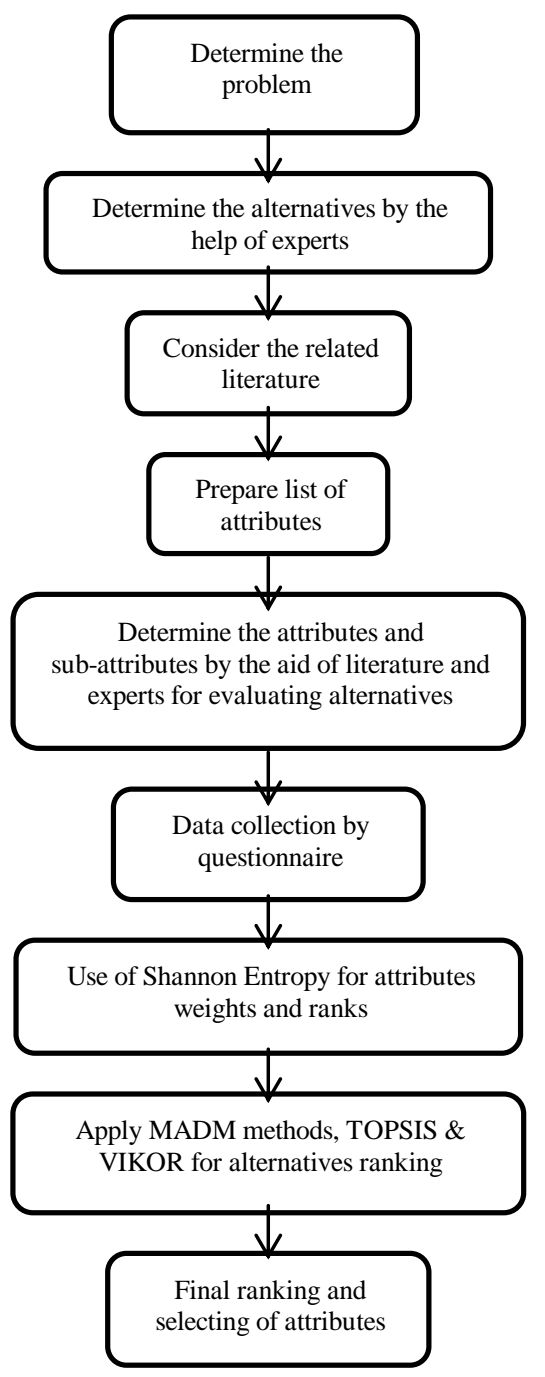

Fig. 2: Procedure of decision making 
Step 3: Define the divergence:

$d_{j}=1-e_{j}$

Step 4: Obtain the normalize weights of indexes:

$w_{j}=d_{j} / \sum d_{j}$

Step 5: Integrate the results by experts' opinion:

$w_{\mathrm{j}}=\lambda_{\mathrm{j}} w_{\mathrm{j}} / \sum \lambda_{\mathrm{j}} w_{\mathrm{j}}$

$\lambda_{j}$ is the experts' opinion about sub-attributes

importance.

\section{B. TOPSIS}

Technique for order preference by similarity to ideal solution, a ranking multi-criteria decision making method, has been applied to rank alternatives preference. This technique was first developed by Hwang and Yoon, based on the concept that the chosen alternative should have the shortest distance from the positive ideal solution and the farthest from the negative ideal solution [10]. In short, positive ideal solution is the one with the most benefits and lowest cost of all alternatives, the negative ideal solution is the one with the lowest benefits and highest cost [24]. At the end, the alternatives are ranked based on their closeness to the ideal solutions. This concept has been widely used in various MADM models, because of 1) its simplicity and comprehensibility, 2) its computational efficiency, 3) its ability to measure the relative performance of the decision alternatives in a simple mathematical form [25]. The steps of TOPSIS are as followed:

Step 1: Calculate the normalized decision matrix:

$\mathrm{n}_{\mathrm{ij}}=\frac{\mathrm{r}_{\mathrm{ij}}}{\sqrt{\sum_{\mathrm{i}=1}^{\mathrm{m}} \mathrm{r}_{\mathrm{ij}}{ }^{2}}}$

Step 2: Calculate the weighted normalized matrix:

$v_{i j}=n_{i j} \times w_{n \times n}$

Step 3: Determine the positive ideal and the negative ideal solution:

$\mathrm{A}^{+}=\left\{\mathrm{v}_{1}^{+}, \mathrm{v}_{2}^{+}, \ldots, \mathrm{v}_{\mathrm{n}}^{+}\right\}=$

$\left\{\max v_{i j}\right.$,if $j$ is a benefit attribute

min $v_{i j}$ if $j$ is a cost attribute

$A^{-}=\left\{v_{1}^{-}, v_{2}^{-}, \ldots, v_{n}^{-}\right\}=$

$\left\{\min v_{i j}\right.$ if $j$ is a benefit attribute

max $v_{i j}$, if $j$ is a cost attribute

Step 4: Calculate the separation of each alternative from the positive and negative ideal solution:

$\mathrm{D}_{\mathrm{i}}+=\sqrt{\sum\left(\mathrm{v}_{\mathrm{ij}}-\mathrm{v}_{\mathrm{j}}{ }^{+}\right)^{2}}$

$D_{i}-=\sqrt{\sum\left(v_{i j}-v_{j}-\right)^{2}}$

Step 5: Calculate the relative closeness to the ideal solution:

$c_{i}=d_{i^{-}} /\left(d_{i^{+}}+d_{i^{-}}\right)$

Step 6: Rank the preference order.

\section{VIKOR}

Opricovic, Opricovic and Tzeng, developed VIKOR, which means multi- criteria optimization and compromise solution [26]. It focuses on ranking and sorting a set of alternatives against various conflicting decision attributes assuming that compromising is acceptable to resolve conflicts. Like other MADM methods such as TOPSIS, VIKOR determines the best decision option based on closeness to the ideal. But, unlike TOPSIS, it applies a ranking index based on the particular measure of closeness to the ideal solution [26]. The steps of VIKOR are as followed:

Step 1: Determine the best $\mathrm{Fi}^{*}$ and the worst $\mathrm{Fi}-$ values for all attributes on the basis of their profit or expenditure nature.

Step 2: Compute the values $\mathrm{Sj}$ and $\mathrm{Rj}$ :

$S_{j}=\sum_{\mathrm{i}=1}^{\mathrm{n}} \mathrm{W}_{\mathrm{i}}\left(f_{i}^{*}-f_{i j}\right) /\left(f_{i}^{*}-f_{i}^{-}\right)$

$R_{j}=\operatorname{Max}\left[\mathrm{W}_{\mathrm{i}}\left(f_{i}^{*}-f_{i j}\right) /\left(f_{i}^{*}-f_{i}^{-}\right)\right]$

Step 3: Compute the value ${ }^{Q_{j}}$ :

$Q_{j}=V\left(\mathrm{~S}_{\mathrm{j}}-S^{*}\right) /\left(S-S^{*}\right)+$

$$
(1-\mathrm{V})\left[\left(\mathrm{R}_{\mathrm{j}}-R^{*}\right) /\left(R^{-}-R^{*}\right)\right]
$$

$S^{*}=\operatorname{Min} \mathrm{S}_{\mathrm{j}}, S^{-}=\operatorname{Max} \mathrm{S}_{\mathrm{j}}$

$R^{*}=\operatorname{Min} \mathrm{R}_{\mathrm{j}} \quad, R^{-}=\operatorname{Max} \mathrm{R}_{\mathrm{j}}$

$\mathrm{V}$ is introduced as a weight for the strategy of maximum group utility, here $\mathrm{V}=0.5$.

Step 4: Rank the alternatives, sorting by the values $S, R$, and $q$ in decreasing order.

1) Select the best alternative on the basis of these two conditions:

$\mathrm{Q}\left(\mathrm{a}^{\prime \prime}\right)-\mathrm{Q}\left(\mathrm{a}^{\prime}\right)>\mathrm{DQ}$

Where $\mathrm{a}^{\prime}$ is the alternative with second position in the ranking list by $\mathrm{Q}, \mathrm{DQ}=1 /(\mathrm{J}-1)$ and $\mathrm{J}$ is the number of alternatives.

Alternative a' must also be the best ranked by $\mathrm{S}$ or/and $\mathrm{R}$.

If one of the conditions is not satisfied, then a set of compromise solution is proposed:

Alternatives $\mathrm{a}^{\prime}$ and $\mathrm{a}$ " if only condition $\mathrm{b}$ is not satisfied.

Alternative $\mathrm{a}^{\prime}, \mathrm{a}^{\prime \prime} . \mathrm{a}^{m}$ if condition a is not satisfied and ${ }^{a^{m}}$ is determined by the relation $\mathrm{D}\left({ }^{a^{m}}\right)-\mathrm{D}\left(\mathrm{a}^{\prime}\right)<\mathrm{DQ}$ for maximum $\mathrm{m}$.

\section{RESULTS}

The weights of seventeen attributes are calculated by Shannon Entropy (Table 1) and then TOPSIS and VIKOR methods are applied for ranking alternatives by the calculated weights (Table 2 and Table 3 ).

\begin{tabular}{cccc}
\multicolumn{4}{c}{ TABLE 1. WEIGHTS OF ATTRIBUTES } \\
\hline \hline $\mathrm{w}_{1}$ & 0.03 & $\mathrm{w}_{10}$ & 0.04 \\
$\mathrm{w}_{2}$ & 0.04 & $\mathrm{w}_{11}$ & 0.08 \\
$\mathrm{w}_{3}$ & 0.10 & $\mathrm{w}_{12}$ & 0.10 \\
$\mathrm{w}_{4}$ & 0.03 & $\mathrm{w}_{13}$ & 0.05 \\
$\mathrm{w}_{5}$ & 0.04 & $\mathrm{w}_{14}$ & 0.06 \\
$\mathrm{w}_{6}$ & 0.08 & $\mathrm{w}_{15}$ & 0.05 \\
$\mathrm{w}_{7}$ & 0.06 & $\mathrm{w}_{16}$ & 0.08 \\
$\mathrm{w}_{8}$ & 0.01 & $\mathrm{w}_{17}$ & 0.03 \\
$\mathrm{w}_{9}$ & 0.12 & & \\
\hline \hline
\end{tabular}


TABLE 2. TOPSIS METHOD RESULTS

\begin{tabular}{|c|c|c|c|c|c|}
\hline & & $\overline{\mathrm{A}_{1}}$ & $\overline{\mathrm{A}_{2}}$ & $\overline{\mathrm{A}_{3}}$ & $\overline{\mathrm{A}_{4}}$ \\
\hline $\mathrm{D}_{\mathrm{i}^{+}}$ & & 0.04 & 0.08 & 0.05 & 0.08 \\
\hline $\mathrm{D}_{\mathrm{i}^{-}}$ & & 0.08 & 0.05 & 0.08 & 0.05 \\
\hline & & 0.69 & 0.40 & 0.58 & 0.39 \\
\hline Ranking & & 1 & 3 & 2 & 4 \\
\hline & \multicolumn{4}{|c|}{ TABLE 3. VIKOR METHOD RESULTS } & \\
\hline & & $\overline{\overline{S_{j}}}$ & $\overline{\overline{R_{j}}}$ & $\overline{\overline{Q_{j}}}$ & \\
\hline & $\mathrm{A}_{1}$ & 0.29 & 0.06 & 0.00 & \\
\hline & $\mathrm{A}_{2}$ & 0.68 & 0.10 & 0.86 & \\
\hline & $\mathrm{A}_{3}$ & 0.35 & 0.12 & 0.57 & \\
\hline & $\mathrm{A}_{4}$ & 0.65 & 0.10 & 0.79 & \\
\hline
\end{tabular}

According to TOPSIS, the alternative which has the biggest $\mathrm{Ci}$ must have been chosen as an ideal solution. And due to VIKOR the alternative which has a $\mathrm{Sj}$ and $\mathrm{Rj}$ smaller than the other alternatives and a $\mathrm{Qj}$ smaller than DQ must have been chosen. Therefore Vanak (A1) is the best alternative.

\section{CONCLUSION}

It is the first responsibility of investors to apply their capital in the right places at right times and earn benefits. However, where to invest and how to invest is a venturous and complicated problem. Multi attributes decision making has been widely used in selecting the well-suited alternative with respect to multiple and usually conflicting attributes [25]. A wide range of methodologies are presented by MADM approach that can help decision makers to overcome the complexity and difficulty of economical decision problems [8]. These MADM methods have been widely used in various fields such as information project selection, material selection, management decisions, strategy selection, and problem relating to decision-making [21].

In this paper, a real world case study from Tehran was presented. At the first step the alternatives and attributes were determined, then the weight of each attribute was calculated by Shannon Entropy, TOPSIS and VIKOR with the aim of obtaining the compromise solution for multi attributes problems. To conclude, the results of both methods, TOPSIS and VIKOR, have shown that Vanak has to be chosen as an alternative location based on all proposed attributes. These methods can be practical for ranking and selecting alternatives with respect to multiple conflicting attributes for the large scale problems.

\section{REFERENCES}

[1] Cheng, E., Li, H., \& Yu , L. (2007). a GIS approach to shopping mall location selection. building and environment , 884-892.

[2] Cheng, E. W., Li, H., \& Yu, L. (2005). The analytic network process (ANP) approach to location selection: a shopping mall illustration. Construction Innovation, 83-97.

[3] Anselmsson, J. (2006). sources of customer satisfaction with shopping malls:a comparative study of different customer segments. the international reviwe of retail, distribution and consumer research, 115-138.
[4] Kuo, R., Chi , S., \& Kao, S. (2002). a decision support system for selecting convenience store location through integration of fuzzy AHP and artificial neural network. computers in industry, 199-214.

[5] Burnaz, S., \& Topcu, Y. (2006). a multiple-criteria decision-making approach for the evaluation of retail location. multi-criteria decision analysis, 67-76.

[6] Dasci, A., \& Laporte, G. (2005). a continous model for multistore competitive location. operations research, 263-280.

[7] Onut, S., \& Soner, S. (2008). transshipment site selection using the AHP and TOPSIS approaches under fuzzy environment. waste management, 1552-1559.

[8] Kuo, Y.-C., Lu, S.-T., Tzeng, G.-H., Lin, Y.-C., \& Huang, Y.-S. (2013). using fuzzy integral approach to enhance site selection assessment-a case study of the optoelectronics industry. procedia computer science, 306-313.

[9] Rezaeiniya, N., Safaei Ghadikolaei, A., Mehri-Tekmeh, J., \& Rezaeiniya, H. (2014). fuzzy ANP approach for new application: greenhouse location selection; a case in Iran. mathematics and computer science, 1-20.

[10] Yaghoubzadeh, N. (2013). a geographic information systems-based decision support system for site selecting of cinema: an example from Tehran, Iran. world of sciences, 12-17.

[11] Rahman, M., Rusteberg, B., Gogu, R., Ferreira, j., \& Sauter, M. (2012). a new spatial multi-criteria decision support tool for site selection for implementation of managed aquifer recharge. environmental management, $61-75$.

[12] Aghdaie, M., Hashemkhani Zolfani, S., \& Zavadskas, E. K. (2013). market segment evaluation and selection based on application of fuzzy AHP and COPRAS-G methods. business economics and management, 213-233.

[13] Vahidnia, M., Alesheikh, A., \& Alimohammadi, A. (2009). hospital site selection using fuzzy AHP and its derivatives. environmental management, 3048-3056.

[14] Kotler P. (1991) Marketing Management, $7^{\text {th }}$ edition (Englewood Cliffs, NJ: Prentice Hall).

[15] Hashemkhani Zolfani, S., Aghdaie, M., Derakhti, A., Zavadskas, E. K., \& Morshed Varzandeh, M. (2013). decision making on business issues with foresight perspective; an application of new hybrid MCDM model in shopping mall location. expert systems with applications , 7111-7121.

[16] Chou, T.-Y., Hsu, C.-L., \& Chen, M.-C. (2008). a fuzzy multi-criteria decision model for international tourist hotels location selection. international journal of hospitality management , 293-301.

[17] Kengpol, A., Rontlaong, P., \& Tuominen, M. (2013). a decision suport system for selection of solar power plant locations by applying fuzzy AHP and TOPSIS: an empirical study. journal of sofware engineering and applications , 470-481.

[18] Kahraman, C., Ruan, D., \& Dogan, I. (2003). fuzzy group decision-making for facility location selection. information sciences , 135-153.

[19] Mohajeri, N. \& Amin, G.R. (2010). Railway Station Site Selection Using Analytical Hierarchy Process and Data Envelopment Analysis. Computer and Industrial Engineering, 107-114.

[20] Awasthi, A., Chauhan, S., \& Goyal, S. (2011). a multi-criteria decision making approach for location planning for urban distribution centers under uncertainty. mathematical and computer modelling , 98-109.

[21] Kuo, M.-S. (2011). optimal location selection for an international distribution center by using a new hybrid method. expert systems with applications , 7208-7221.

[22] Shemshadi, A., Shirazi, H., Toreihi, M., \& Tarokh, M. (2011). a fuzzy VIKOR method for supplier selection based on entropy measurefor objective weighting. expert systems with applications , 12160-12167.

[23] Singh, V. P. (1999). the entropy theory as a tool for modelling and decision-making in environmental and water resources. water $S A$.

[24] Choudhary, D., \& Shankar, R. (2012). an steep-fuzzy AHP-TOPSIS framework for evaluation and selection of thermal power plant location: a case study from India. energy, 510-521.

[25] Yeh, C.-H. (2002). a problem-based selection of multi-attribute decision-making methods. international transactions in operational research, 169-181.

[26] Sanayei, A., Mousavi, S., \& Yazdankhah, A. (2010). group decision making process for supplier selection with VIKOR under fuzzy environment. expert systems with applications, 24-30. 